\title{
The Nature of E Companies and Their Legal Regulations
}

\author{
Dr. Farouq Ahmad Faleh Al Azzam \\ Assistant Professor \\ Faculty of Law \\ Jadara University, Jordan \\ Dr. Mueen Fandi Nhar Alshunnaq \\ Assistant Professor \\ Faculty of Law \\ Jadara University, Jordan
}

\begin{abstract}
As a result of the developments in the means of communication which has entered into all aspects of life, it has become more necessary to conduct business transactions via means of communication and modern technology by the public and private companies to avoid the obstacles that they suffer from when relying on traditional methods in increasing their profits. Using means of communication and modern technology enables these companies to conduct many commercial transactions and services quickly so they save time and effort. In addition to attracting customers from around the world to increase their sales. Nevertheless, Many e - commerce companies have faced various obstacles that are related to the operation systems, which makes them vulnerable to hackers attacks, and reputation risks that arose from the lack of means of data protection that are protected by the e company in addition to legal risks that it may face. This research aims at explaining the concept of e companies and to specify the principle behind it as well as its legal regulations, despite the fact that the legislations are free of specific regulations of this type of companies.
\end{abstract}

Keywords: Electronic Companies, Electronic Commerce, Jordanian Electronic Legislation, Commercial Transactions, Internet.

\section{Introduction}

The development of communications, especially information technology, has led to the development of modern life in various fields, especially the field of electronic commerce. The internet has become a tool that reduces time, space, effort and costs (Abu el Ela, 2004, p.7). E-commerce is a business that is carried out through electronic coordination between two parties, where transactions and contracts are concluded by using a computer without the need for direct contacts between the contractors (Janabihi \& Janabihi 2005, p. 8).

The rapid development in the world of e-commerce has also led to the emergence of e-companies, where the term has been traded and used recently. What does this e-company mean? What are their characteristics? Does traditional corporate law apply to it? Do these companies need infrastructure, technology and culture together? What problems and obstacles are they facing? How widespread and used are they in Jordan? What is the law governing it?

Especially, that this trade according to Jordan Electronic Transactions Law No. (85) of the year; Electronic Transactions Law No. (15) of 2015; and Electronic Payment System No. (111) of 2017 is carried out through a computer and the international network of telecommunications, which require special legal rules commensurate with this commercial environment which promotes many countries to impose law regulating this kind of commerce.

The UNCITRAL Model Law on E-commerce of (1996), have promoted countries to set a special law for this trade in order to facilitate transactions that are carried out through this type of network and to protect their clients from the risks they may be exposed to. The Jordanian laws and legislation have also worked out on this issue .

It should be noted that there are several factors that helped the emergence of e commerce companies as the development of financial services. These e companies have become a component of the economic progress of each country, which contributed to the development of trade and converted from traditional to modern. The most prominent of these developments is the emergence of e-commerce companies that have virtual sites and have no location on the ground. They can establish a company based on the internet and deals with the public in the field of commerce and establish a website instead of creating a location on the ground that cost more and need effort to reach the rest partners and the customers easily. 
Their dealing will be acted via the Internet anywhere (Munji, 2002, p. 315) through a computer screen, where negotiations, contracting, inquire about transactions and offers provided by the electronic company are conducted electronically. This research will be divided into three sections: in the first section what are electronic companies? The second section, the legal organization of electronic companies. The third section will discuss the reality of the application of electronic companies in Jordan .

\section{What is e company?}

E companies are closely related to e commerce. This concept of e commerce is a new one that explains the process of selling, buying, exchanging products, services and information through computer networks, including the Internet. Radwan (1999) defines it as a combination of integrated business processes that all institutions and individuals deal with, and it depends on electronic processing.

Through the previous definitions it can be said that e commerce is the performance of the process of commerce and service electronically in another word, it is mutual operations whether commercial or service and with the presence of parties dealing with each other when using this type of methods, in addition to the presence of technology or electronic means.

\subsection{The concept of e companies:}

The purpose of e companies is to bring the owners of companies together in virtual trade centers in order to display their goods, services and their companies' shares to the public by means of an electronic service via the Internet and it is open to all its users. These digital enterprises as virtual centers that can be divided into two main categories:

1- Companies that can be accessed without the need to follow certain instructions or procedures so that the visitor to the site of the company can navigate around to see the goods and services without being able to buy, and this type of centers is a means of modern advertising through which companies attract customers as a means to increase the volume of sales (Abu el Ela, 2004, p.15).

2- E commerce companies that conduct their business through the Internet by displaying their products and services through entering the sales pages and contracting on these products, the company's virtual site does not exist on the ground. The establishment of these enterprises, the agreement and documentation of the contract and the negotiations between the founders of the company are done through the electronic network. On the other hand, the conclusion of the contract of the company can be also concluded in its known traditional form. According to the Jordanian Companies Law No. (22) of 1997 and its amendments the e company consists of two parts that are:

3- (a company) It is a contract that obliges two or more persons to participate in the provision of a share of money or work or both to share the profit and loss resulting from such activity(Atwi, 2005, p. 19). (electronic) Describe the field of performance of the activity specifically, business activity using electronic means.

The e-commerce company is defined as a system operating in the field of e-commerce, and when referring to the traditional description of the contract of the company, it stipulated that the company is a contract .Therefore e company contract does not differ from the contract of any other company, because the contract is the source of the commitment of partners that require the willingness of the parties to be held. The parties' willingness is expressed through the Internet via a computer and in the form of electronic messages, including the call to negotiate the conclusion of the company's contract under certain conditions, or an offer and acceptance by another party although there is no physical presence between the parties (Ouden, 2005, p.23).

Accordingly, we conclude that an e company is a contract between two or more parties to establish a business that aims to make a profit and to be operated through electronic messages through the World Wide Web. Article (11) of the UNCITRAL Model Law indicates that (In the context of contract formation, unless otherwise agreed by the parties, an offer and the acceptance of an offer may be expressed by means of data messages. Where a data message is used in the formation of a contract, that contract shall not be denied validity or enforceability on the sole ground that a data message was used for that purpose).

The term "contract formation" mentioned in article (11) of the UNCITRAL Model Law is an absolute indication of all types of contracts, including the contract of an e company. E commerce companies have also been identified as a modern trade method in bringing views together views to carry out negotiations, contracting and establishing these companies via the Internet (Munji,2002, p. 255).

\subsection{The advantages of e companies.}

The most significant advantages of e companies are the reduction in costs. Companies usually allocate a lot of their budget to open new branches in all areas to get closer to the customers, but now they don't need to do so as they now come closer to customers in a better way. 
In fact, it only requires a click to access e commerce sites whether you are in your house or at work. You can also know about their activities, services, prices and all the data needed by a customer. On one hand, these e commerce sites save a lot of expenses and costs and on the other hand, they save a lot of time to reach as many customers as possible .It can be said that e companies have beneficial features for the company itself, the consumer and society. As for the advantages of the company itself, it helps to expand the scope of its market from the domestic market into the international market, and it can find new partners and consumers in an easy and fast way(Janiah \& Janabihi,2005 p. 176)

In other words, e commerce companies have access to large base of the public. Communication is done through intensive use over the Internet, which in turn will overcome the time and space barrier in which one is dealt with by the parties in moments through audio-visual communication (Mansour, 2003, p23).

As for the individuals and the community in general, this type of companies with the goods and services, they provided through the Internet will enable the consumer to conclude the deal within minutes and from anywhere on the globe, especially if the goods and services are provided by more than one company which gives the customers the chance to choose the best while this is not available in the case of companies of traditional sense, that requires visiting each geographical location of the company to choose. While for e commerce the best offers of goods and services in the e sites will certainly lead to a kind of legitimate competition to provide the best service and encourages the law income and limited income customers to deal with this type of companies.

The most prominent characteristic of this type of companies is the lack of paper documents exchange in the conducting and implementing of transactions between the partners on the one hand and between the company and the consumer on the other hand, all transactions are conducted electronically without the use of paper document, then e message as written evidence and a legal document to prove in the case disagreement (Abu el Ela,2004, p. 18).

It can be said that the advantages of e commerce companies are the possibility of access to a broader base of clients and to provide new and full e services as well as reducing operating costs and increasing the efficiency of performance.

\subsection{The risks of e commerce.}

There are several risks arising from the work of e commerce companies, the most important is the relationship between the client and the company that deals with him, although it appears natural, but in fact it is of greatest danger that threat companies because it based on electronic data exchange between the client and the e company without verifying the authenticity or the character of that client who may provide a correct or false data for the purpose he certainly aware of when providing such data to the company and he is certain that the company will not be able to detect it. The result of the entering these data may be to oblige the company to do business for the benefit of that client for burglary of large amounts of money on the basis of those incorrect data. The company may also be subject to an organized fraud by its clients who are trying to work with it for the purpose of the scam and seizure of large amounts of cash, accordingly, the necessary technology must be developed to prevent these actions.

There are also problems and risks facing e companies in dealing with the public which are the lack of presence of the parties to the contract in one place and these risks are affecting both parties alike. For the e company when dealing with its subscribers by emails exchanged from both parties without verifying the accuracy of the given data and the character of the contractor who is certain that the company will not be able to reveal the truth and this means the possibility of the company's exposure to fraud by the customers, and at the same time (Janabihi \& Janabihi ,2005,p. 17).

In some jurisprudence (Hijazi, 2002, p.31.) dealing with these companies expose the customers to deceit or mistakes when it advertises and promotes its propaganda means for a commodity different from the required specifications because there is no possibility of examination and inspection of the commodity and that the consumer often lacks the experience that enables him to understand the terms of the contract, while Another aspect is that it is difficult to consider that the consumer is always the weak party in dealing with this company as long as there are negotiations before the contract, which enables him to detect all the terms and parts of the contract( Abu el Ela,2004, p. 22).

Dealings through e-companies presents a serious issue that the site may be exposed to hacking and piracy that aim to attain economic information or personal data or knowledge of the financial position, which loses the status of privacy so that the hackers with experience in this area of abuse access the company's website ( Abu el Ela, 2004 p.25.), And this type of companies may be exposed to the problem of viruses in the computer programs that attack the network and cause destruction of the company's electronic programs, which affects the reputation of the company and the confidence of the customers, These facts has prompted companies in the world to seek protection through some procedures to reduce these risks (Abu el Ela,2004, p. 25). 
In addition, there are some legal risks in the case of violation of laws and rules, especially those concerned with the protection of consumers in some countries or the lack of legal knowledge of some agreements concluded by using electronic means. It can be said that dealing with e companies have the risk of finding the law that can be applied to resolve conflict between Its members or the contractors and how to prove the contract, especially the legislative regulation in many countries, which did not notice some of these types of companies.

The misuse of dealing with e companies that can exploit their knowledge of the Internet technologies when contracting with these companies to achieve illegal activities.

The spread of the phenomenon of globalization allowed the removal of restrictions and exceeding the limits . Then increase foreign investment, which plays an important role in expanding economic activity of the State. This phenomenon has led to the abolition of all restrictions, barriers and distances towards the international trade movement and the movement of capital under the umbrella of foreign investment, especially in developing countries, where investment projects are carried out by an enterprise from outside the country to participate and exercise some influence on the operations of these projects (Abdel Salam 2004, p.7).

E company's activity could be an electronic bank service that provide its banking services to the public through electronic transactions that may be exploited by some to achieve their illegitimate objectives by withdrawing money or depositing the amounts resulting from illegal trade or smuggling in order to camouflage the real source, which is called money laundering. E-banks have a role in attracting foreign investment and providing credit facilities on the basis of the gains made by the national economy, especially in developing countries, while some may exploit the investment to control this economy to achieve certain economic goals (Badawi, 2005, p .65).

Finally, it can be said that there are multiple risks to electronic companies, the first of which is the operating risks such as inadequate systems insurance, inappropriate systems design, work completion or maintenance and abuse of customers. The second is the reputation risk because of lack of adequate protection for data that the company retains and the intrusion by outsiders which affects the reputation of the company, and the third is the legal risk in case of violation of the rules established for the company and customers.

\section{Regulating e companies.}

It is known that traditional companies are trying to turn their internal and external business into an electronic system to expand their business and save time, effort and costs and even benefit from the advantages of e-commerce. But the question is, what steps should be taken to achieve this. To answer this question, it is possible to say that there are some procedures and steps to carry out this process, the most important of which are:

1 - Choosing the appropriate name or domain. That is the right name for the company's identity which through its consumers, businesses and visitors can easily access to purchase their products (Colin, 1995).

2 - Website building. After the completion of the selection and registration of the name, the site is established on the company's website; this site will be the frontage or trade show of the company. It works as a record that contains information and advice that interested customers and the one who is interested to know about the company, its products, services and prices. It also contains the success certificates mentioned by clients and customers who have dealt with the company previously and also it contains a page to answer customer inquiries and receive their comments and suggestions so as to leave a distinct impression for all visitors to the site of the company.

3 - Choosing a website to host the company's website. Choosing an internet service provider is similar to choosing the geographical site of the company's offices. The service provider is chosen either on a company's web server or in a network server with another company. The importance of the services provided by a service provider is to web hosting and to provide space on the computer in order to save the files, pages of the website, provide access to the internet and tools to administer the site, e-mail and other supportive services.

4-The security of the site. In the modern era, different types of security threats have been increased and threats the websites such as spoofing, which copies from pages of companies' sites and building illegal sites that duplicate the real site interface of the company in order to deceive visitors and fraud them like eavesdropping, which is conducted in the case of non-encryption information such as intentional vandalism or alteration of information in which some pages are changed and abuse the company. Therefore, the company must, first of all, work on documenting and securing its sites for the safety and maintenance of its data and reassuring customers that their credit cards and personal information are protected and not subject to misuse (Colin, 1995).

5 - Facilitate the payment process. The electronic companies facilitate the payment of products and services through credit cards. 
The payment process is conducted through the electronic way through programs linked to the website of the company administered by specialized financial institutions and handles the financing after the customers enter the payment data, which is encrypted through the technology of communication between the browser of the customer and the web server that contains the website in the company.

After these steps, it is necessary to market and publicize the electronic company through advertising it in search engines (Suleiman, 2004.) such as yahoo and the television commercials advertisements, radio stations, magazines and newspapers. It should be noted that there are two ways for marketing and advertising through the Internet which are marketing using e-mail and marketing using the web.

\subsection{How to conclude an electronic company contract:}

The electronic company can be established in a traditional manner, like any other companies, with a meeting between the founders signing a contract in which certain items are met. Thus, the activity in the electronic field is carried out through the Internet. The e company is also established by means of what is known as the electronic contract. It is a contract, like all other contracts, concluded with the availability of its known traditional items, but is described as electronic in accordance with the method or means by which the contract is concluded; it is created by acceptance and affirmation between the parties by audiovisual means via the international network (Mansour, 2003, p. 8).

Some of the questions posed in these subjects are: how to conclude the electronic contract? Is there a possibility to apply the traditional rules for the establishment of the company in its known concept and its realistic presence on the ground? Or are there any other ways to establish an e-company? Is there a possibility to apply the traditional rules for the establishment of the company in its known concept and its realistic presence on the ground? In accord to the Jordanian Companies Law No. 22 of 1997 and its amendments we obtain that the establishment of the company requires a contract prepared by the founders and a site that was established by them or their representatives.

The concept of establishing a company is legally defined as a set of acts that require the creation of this legal entity in a way that does not contradict with the legislator's will and in accordance with the legislative texts governing it. These acts are carried out by a group of people called the founders of the company (Masri, 2005, p. 132).

Due to the fact that the legislations do not address these types of companies or regulate them in special laws, we must refer to the traditional rules and indicate their applicability to the electronic companies.

Generally, the commercial company is a contract that requires the availability of its general elements to be considered valid. These general elements are the consensual, the position and the reason, as well as the substantive elements which are the formalities elements required by establishing the company contract. Therefore, the contract to the electronic company is concluded by the desire of the parties to creating a certain legal effect, namely the establishment of the company, so the available of the parties will is recommended at the conclusion of the contract, which is expressed either verbal, written or by indicating consent (Atwi, 2005, p. 22).

It can be said that the founders of the e company wishing to establish such a company can exchange the offer and acceptance, preceded by deliberations and negotiations between the founding partners by means of data messages in which all the information is recorded through the Internet. The negotiation process is of great importance for the successful conclusion of this company in all its technical, financial, administrative and legal aspects (Albany, 2004, p. 14). And to identify the other contractor and determine the content of the contract of the company in terms of type and nature of its activity and the extent of the responsibility of the partners. The question that arises in this area is what is the benefit of negotiation in such these companies?

To answer this question we should explain that the contract of the e company is a remote contract and not between the two existing parties, which raises the doubt between the parties, uncertainty of the negotiator's personality, the extent of real credit and financial reputation, which motivating each party wishing to join the company to query about its situation joining it. The establishment of an electronic company may require the use of technical, legal and accounting expertise to increase confidence in its formation. It has become known that modern technology has provided direct means of communication on a degree of progress. Satellite and fiber optics are negotiated by visual conferences and interviews via the Internet and this saves time and expense required by the conclusion of traditional companies (Mansour, p. 52).

According to the Jordanian Companies Law No. 22 of 1997 and its amendments, If the parties reach the negotiations successfully, they will be moved to the next step that is the contract, which is concluded by the electronic message indicating that the offer and acceptance are consistent with the provisions of the law and that the offer and acceptance shall be in written (Nassar, 2004, p.44). This agreement shall be documented by a contract, but how to sign at the time that each member of the company is in a different country with hundreds of miles away and they are only to connect through an electronic network? 
In fact, the answer to this question is this. It is not required to sign, but to be a clear indication of the owner and unambiguous indication that his will went to the commitment to the company contract. Since the establishment of e companies is done through the Internet, it is difficult to imagine the use of traditional signature that is writing the name of the parties in a normal way or a distinctive symbol because of the impossibility of the conclusion of a traditional contract signed by the parties through the lines of this network, Thus, science has developed a modern technical means commensurate with the work of electronic commerce an electronic signature consisting of letters, numbers, symbols or signs of a single character that allows the signature person to be identified and distinguished from others and is accredited by the competent authority(Janabihi \& Janabihi, 2005, p. 190).

Therefore, we believe that it is possible to establish an electronic company with the agreement of the parties and sign it electronically with a set of symbols, numbers or electronic characters that indicate the personality of the site, regardless of the forms of this signature (Ouden, p. 181). According to some jurisprudence, this type of signature has the legal authority to sign in its traditional form (Janabihi \& Janabihi,2005, p. 31). This is what was indicated by the UNCITRAL Model Law of the United Nations, and here we reach the stage of establishing the electronic company with its general objective elements of compromise, situation and reason.

In accordance to the general rules stipulated in the Civil Code; the rules of eligibility and willingness on one hand and of being free from defects and indications of eligibility on the other hand. And that the contract of this company is legitimate and possible, the reason for contracting is not contrary to law and public order (Atwi,2005, p.22 ) and with regard to the special substantive elements of the conclusion of the company's electronic contract, the specific objective elements of the company contract are limited to multiple partners, the intention to participate, the sharing of profits and losses, and the provision of quotas.

As for the other requirements of a company, such as taking the company's trade name or trademark, if the company's activity is focused on the production of a certain commodity, it is imperative to follow the rules prescribed by the legislator in the laws of trade names, such as registration in the chambers of commerce and industry allocated to that, Commercialization and documentation of the contract to official bodies determined by the law that will regulate the work of electronic companies.

\subsection{Types of e companies}

There are three types of electronic companies: electronic advertising companies, electronic companies with simple services and integrated electronic companies.

1- Electronic advertising companies. They are companies that follow the style of electronic advertising and have a site on the ground to exercise through it the purpose for which it was created, so it is established on the Internet as a kind of modern advertising means to bring more customers without providing any kind of transactions of the company, it is only one type of modern advertising that the company is holding as propaganda for its products or services.

2- Electronic companies with simple service. These companies are trying to achieve two goals from their website, the first of which is advertising and the other is providing simple services for customers to facilitate the procedures that should move to the company's headquarters to complete procedures such as filling the forms of acquaintance or forms that show the purpose of customers from dealing with that company only.

3 - Integrated electronic companies. These electronic companies are fully active through the Internet and have no branches on the ground that the customers can do all their work with that company through its website, and this company exercises all its purposes through the Internet without the need for a traditional site on the earth (Atwi,2005, p.34).

Companies that are mentioned in commercial law are divided into two main types: partnership companies and corporations. Partnership companies are based on the personal consideration of the partner and the mutual trust between the partners, which means that the partner cannot dispose of his share without the consent of the other partners. His membership ends by his death, seizure or bankruptcy, These companies are based on the personal consideration of the partner, and the responsibility for the debts of the company is the responsibility of unlimited personal solidarity (Ahmed, 2003, p. 61.), of all types (general partnership, simple company and sole project).

While the corporation's companies are based on financial consideration only, the liability in these companies are limited to the nominal value of the contribution to the capital of the company one type of these companies is the joint stock companies and limited liability companies.

After this rapid review of some types of companies, there is a question that imposes itself; under what type of electronic companies, especially with the absence of comparative legislation of the regulation, is this type of companies? 
I think it is possible to apply the rules related to the types of traditional companies in line with the nature of e companies, whether it was founded under the umbrella of corporation companies or partnership companies (Baldawi, 1990 p. 23), but there is an important and a very serious issue that is the personal nature of the companies of partnership type and that the personality of the partner is in consideration which demand a close relationship and mutual trust between company members, which is difficult to achieve if not impossible in e-companies whose members may not belong to one country, they are separated from each other by borders and distances so it is difficult to gain confidence and knowledge in these companies because the conclusion of a contract between partners will be remote, that is, there is the spatial boundaries between the contractors and these are similar to the contracts signed by post, telex and fax (Albany, p. 14). The issue of the transferring the partner's share to non-members of the company can only be excluded with the approval of all the members of the company and not opposing the other partners, according to the general rules of the companies of partnership.

As for the establishment of an e company with limited liability, which is under the scope of the corporation companies, it is not dangerous as long as the company is based on financial consideration, the member of the company may not know the other party and what connect him with the company is his company's shares. These shares can be transferred to others without conditions, except indicating it in the electronic records of the company in respect of the conduct of shares. This leads us to say that the e companies must fall under the type of corporate companies as long as the liability in this company is limited and non-solidarity, the importance of this is when the company is bankrupted and unable to pay its commercial debt but this does not constitute a risk to the shareholders of the company as long as the bankruptcy does not extend to their own financial (Baldawi, 1990, p.115).

In discussing how e companies runs, it is necessary to make use of and apply the rules for the traditional management of the company, especially with regard to the authorized director of the company and the public authority. In addition to the presence of the board of directors in the joint stock company. The company runs via Internet even for the meeting of the members of the General Assembly as the meeting is scheduled and reported on the network also, in less time and expenses (Atwi, 2005p.250.), and then members hold their meeting remotely, all in his city or state with a closed meeting and electronic mechanism to exchange views, proposals, discuss the agenda and then vote on the decision taken at this meeting.

\subsection{The effects of establishing an electronic company:}

When referring to the general rules in the establishment of the traditional company, we find that the completion of the procedures of the establishment and documentation of the contract with the registrar of companies, who in his turn issue the certificate of the establishment of the company and then give the company its legality (Baldawi, 1990,p. 42). However, it is almost different in e-companies because there is no explicit legislative text that specifies how to register and advertise this company, but we may be able to assist the text of Article (5) of the UNCITRAL Model Law on Electronic Commerce which stated that "Information shall not be denied legal effect, validity or enforceability solely on the grounds that it is in the form of a data message". This means that simply documenting the contract and signing it electronically in data messages will be sufficient to consider that the company has been founded, is known to the outside world and will subsequently acquire a moral personality that will make it independent from the entity of its members. The electronic company acquires the legal personality once the traditional or electronic incorporation procedures have been completed and becomes a stand-alone entity, despite the fact that it is not subject to the law of a particular country as in the case of the traditional company, and enjoys all rights that are contrary to their nature ( Hijazi,2002).

Accordingly, companies enjoy its financial independence apart from the accounts of its partners. And to have a trade name derived from its activity and specifies its type taking into account the provisions of the trade name for the companies of partnership which must include the name of one of the partners at least, in light of the nature of the responsibility of these companies if they are within the partnership companies. When referring to the general rules in the establishment of the traditional company, we find that the completion of the procedures of the establishment and documentation of the contract with the registrar of companies, who in his turn issue the certificate of the establishment of the company and then give the company its legality (Baldawi,2005 p. 42). As for the home, any place where the company's management center is located, it cannot be imagined in terms of e-companies that have a virtual location on the Internet.

Atwi (2005) explains that as for nationality, some believe that nationality is not proven for the moral person because it is an association between the individual and the state. However, we believe that the e company should gain the nationality. It is important to determine the law applicable to the disputes that arise between the members of the company and the disputes that arise between the company and the public. 
There are the traditional criteria that are represented by the standards of location of the company establishment or the central administration, monitoring or control.

Redah (1994) indicated that it was difficult to determine the nationality of an e-company in accord to the standard used to define it. There are the traditional criteria that are represented by the standards of location of the company establishment or the central administration, monitoring or control. All these standards are impossible to find in the system of establishing e-companies because it is difficult to define any standard precisely because the work of companies is centered on a network via the Internet service, and with this difficulty new standards and controls of the nationality of the company have emerged as the decision-making standard whereby the company acquires the nationality of the country where the headquarters of the basic decisions of the company.

Abu el-Ella ( 2004) stated that e-companies are generally established via the Internet web by using the means of communications and e-mails, its members are of different nationalities, the partners in this case and in accordance with the rule of the contract of the law of the contracting parties, agree on the law of the country that applicable to its activity or agreement among them to resort to arbitration, the Agreement shall be in clear and explicit language in the conditions of establishment of the company.

\subsection{The nature of $\mathbf{E}$ Company and its legal termination.}

Through the previous discussion of electronic companies, it is clear that there is a similarity between the moral person of the companies and the moral person in the electronic companies, but they differ only in the manner of forming the contract and the manner of practicing the company's activity to achieve the purpose for which it was founded. Through the previous discussion of electronic companies, it is clear that there is a similarity between the moral person of the companies and the moral person in the electronic companies, but they differ only in the manner of forming the contract and the manner of practicing the company's activity to achieve the purpose for which it was founded .

With regard to the termination of e-companies, I can say that the agreement is the most common way to terminate it, in addition to the reasons for the termination of the traditional companies and the most important ones according to the Jordanian Companies Law No. 22 of 1997 and its amendments are: The completion of the project that the company was established for or the impossibility of the implementation, merger of company, transformation of the company to another type, the General Assembly decision of liquidation and dissolution of the company. That once the electronic company has acquired the moral personality, it will acquire its financial liability, a commercial name, nationality and legal capacity.

\section{The reality of the application of electronic companies in Jordan.}

According to Sahawneh (2003) the reality of electronic companies in Jordan is still in its early stages. Commercial exchanges through electronic companies (buying and selling) are limited operations. Most of these transactions are carried out through private initiatives from the private sector due to the lack of some elements of the infrastructure necessary to develop e-commerce. Which need to increase the level and development of information technology in order to ensure a differential advantage for Jordan in the future knowledge-based economy. " Moreover, the spread of computers and Internet in Jordan is still limited, and the degree of awareness about e-companies is simple, which is considered the most important obstacles to companies. The ESCWA conducted a survey of (30) companies in Jordan through which they were able to identify their views and their knowledge of electronic commerce in general and electronic companies in particular. They found that this concept is still unclear to consumers or traders and most of the commercial establishments in Jordan have websites targeted to attract customers and propaganda work and often does not aim to sell, But the most important feature of Jordan in this area is the human resources available in the field of information technology. But the problem is that there is no real and effective role for the institutions involved in promoting e-commerce such as Amman Chamber of Industry and Commerce. The activities carried out by Chambers of Industry and Commerce are limited and do not amount to competition at the international level, despite the fact that international institutions in Jordan play a large role in raising awareness and promoting electronic commerce by providing financial and technical support to public and private-sector institutions in order to reach the Jordanian's market to global markets by activating the work of companies for e-commerce and have websites to market these products, where the European Union funded the proposed project from the Amman Chamber of Industry to remove the obstacles of electronic commerce in Jordan, especially companies.

Article (3) of the Jordanian Electronic Transactions Law defines its objectives as to facilitate the use of electronic means in transactions' procedures, with due regard to all other Laws and without amending or deleting any of these provisions. And to recognize electronic means of contracting and proofing (electronic transactions, records, electronic signatures, messages, authoritative evidence, acceptance of existing means of a contract and evidence). 
Moreover, the purpose of this law is to provide legal regulation of electronic commerce to ensure confidence in them, encourage their spread in the markets, and this applies to electronic companies .

Based on Article (4) of the Jordanian Electronic Transactions Law, the provisions of this Law shall apply to the following: electronic transactions, electronic records, electronic signatures and any electronic data messages. This is a central requirement for e-business. As for the reality of electronic service companies in Jordan, I can say that Taxi Cream and Uber are the best example of the reality of e-businesses offering services. It should be noted that these companies are not Jordanian origin, but follow the parent company, which has a major center and branches in the Arab region and provides transportation service to people through their contacts with the company, which has websites on the Internet. Finally, we hope that the development of communication methods, the increase in their spread in Jordan, the development of their use and reduce of the cost will lead to the activation of electronic commerce, especially the work of companies in the electronic trading environment and address their problems through rules and legislative measures that are appropriate and understandable for all levels.

\section{Conclusion}

At the end of this research on electronic companies, which dealt with nature and organization of electronic companies, their characteristics, types and risks, the effects of the work and the reality of electronic companies in Jordan, we must indicate the most important findings and recommendations that we reached.

\subsection{Results}

1.E-commerce is a professional business carried out through electronic means and by means of electronic data messages between the parties and the contract (ie, remote contracting).

2.There are many Arab and foreign countries who have regulate this type of trade legislative organization because of its importance.

3.Electronic companies are one of the forms of e-commerce, which establish virtual sites on the Internet and have no real sites on the ground.

4.There are types of electronic companies, which purpose is to advertise and promote their goods and services, and companies that engage in professional business activity and conclude business deals with the public.

5.The contract of the company is held with the availability of the general objective elements of compromise, situation, reason, as well as special objective elements.

6.E-businesses Advantages have significant advantages the most important of which is that it is possible to reach a broad base of the public easily and with simple expenses, which facilitates the consumer to conclude transactions with them. On the other hand, there are some risks that are reflected in the company's inability to identify closely the personality of the member or partner and even the client that may fall in error or fraud by the company.

7.The electronic company contract is authenticated by using the electronic signature which has the legal authority of the traditional signature.

8.Electronic companies may be established under the umbrella of corporation companies or general partnership companies.

9.The electronic company shall acquire the legal personality as soon as the contract is authenticated electronically and signed by the partners as there is no possibility of registering the contract before a competent official authority.

10.The e-companies termination occurred in the same manner as conventional ones.

\subsection{Recommendations:}

- The necessity of legislating a special law in Jordan to regulate the provisions of electronic companies, so that such legislation provides real security for the parties to the legal relationship.

- The need to develop a national strategy for the work of electronic companies because of the advantages provided by these companies and positive features and translated it into work programs carried out under the supervision of a technical committee competent in this area.

- To avoid the risk of dealing with electronic companies, the legislator can impose restrictions on the establishment of an electronic company to protect the site of the company from penetration and disclosure of transactions and secrets of trade as well as impose financial sanctions to anyone who attacks the site with the intention of destroying by electronic viruses.

- To ensure the seriousness of the establishment of the company and to prevent manipulation and fraud in the funds of partners and founders therein should be allocated an official body that is responsible for the establishment of the company ,checking its request register the contract and having a copy of the contract to ensure that the seriousness of the company's activity is in line with the national economy. 
- It is possible to establish specialized regulatory bodies in the field of banking so that these companies will not be exploited by the owners of illegal funds in order to disguise and conceal their true source by introducing them into banking operations aimed at laundering these funds.

- The Jordanian legislator would prefer to limit the establishment of e-companies within corporations' companies that have limited liability, and to exclude its establishment as a kind of general partnership companies with personal consideration and unlimited liability because of the seriousness of their work.

- The need to ascertain the infrastructure, and whether this structure allows the expansion of the scope of this company

- Benefit from the experiences of countries that have fought in this area, such as European countries.

\section{References}

Abdel Salam, S ,A (2004) World Trade Organization and Foreign Direct Investment, Dar Al-Nahda Al Arabiya, 2004. Abu el Ela, A,(2004), practical and legal problems in electronic commerce, 1, Dar Abu al-Majd.

Ahmed, I, S,(2003) The company contract and jurisprudence, 1, the modern university office.

Al bany, N B (2004) Conflict of Laws in Disputes of Electronic Commerce, Master Thesis, University of Baghdad.

Atwi, F(2005) Commercial Companies, i 1, Al Halabi Publications.

Badawi, S, (2005) The Role of Transnational Corporations in Attracting Foreign Direct Investment to Developing Countries, Dar al-Nahda al-Arabia.

Baldawi, K,(1990) Commercial Companies, Dar al-Kut Books, 1990.

Colin, S (1995) Electronic Commerce.

Hijazi, A, Ba (2002) Legal System for the Protection of Electronic Commerce, University Thought House.

Janabihi, M \& Janabihi ,M (2005) Electronic Companies, University Thought House, 2005.

Mansour, M, H (2003) Electronic Responsibility, New University House.

Masri, A, Mustaf,(2005) Legal Controls of Business Theory, New University House.

Munji, I(2002)Technology Transfer Contract, Legal Regulation of Technology Transfer and Electronic Commerce Contract, i., Knowledge Establishment, Alexandria.

Nassar, S (2004) Commercial Companies, Section II, I 1, Legal Library, Damascus.

Ouden, S, A (2005) electronic contract, knowledge facility.

Radwan, R (1999) The World of Electronic Commerce, Arab Organization for Administrative Education, Egypt.

Reda, Y ,A (1994) Legal Aspects of the Group of Transnational Corporations, Dar Al Nahda Al Arabiya.

Sahawneh, M (2003) Foundations of the Application of Electronic Commerce in Institutions, University of Jordan .

Suleiman, A (2004) Trade Exchange, The Basics, Globalization and E-Commerce, Jordan.

\section{Laws and website}

Electronic Transactions Law, Jordan No. 85 of 2001; and Jordanian Electronic Transactions Law No. 15 of 2015. French law on the adaptation of the law of proof of information technology and electronic signature No. 230 of 2001. Jordanian Companies Law No. 22 of 1997 and its amendments.

Jordanian Electronic Payment System No. 11 of 2017.

UNCITRAL Model Law on Electronic Commerce, 1996. 